\title{
Tobacco smoking among secondary school students in NSW
}

\author{
Michael Giffin ${ }^{\mathrm{A}, \mathrm{B}}$ and Margo Eyeson-Annan ${ }^{\mathrm{A}}$ \\ ANSW Health Survey Program, Centre for Epidemiology and \\ Research, NSW Department of Health \\ BCorresponding author. michael.giffin@doh.health.nsw.gov.au
}

In New South Wales (NSW), it is illegal to sell or supply tobacco to a person under 18 years of age. Most people who become long-term smokers start smoking in their teenage years. Early uptake is associated with heavier smoking and greater difficulty in quitting. Preventing adolescents from becoming regular users of tobacco is an important goal of tobacco control programs in Australia. ${ }^{1-4}$

In 2005, the New South Wales School Students Health Behaviours Survey asked students aged 12-17 years a range of questions about smoking prevention, behaviour, addiction and influences. This article describes results for selected questions. Further details on the survey methods, questions asked and complete results for smoking and other health behaviours can be obtained from the New South Wales School Students Health Behaviours
Survey: 2005 Report at http://www.health.nsw.gov.au/ publichealth/surveys/index.asp. ${ }^{5}$

\section{Results}

\section{Smoking prevention}

In 2005, among students aged $12-17$ years, $92.4 \%$ had a lesson or part of a lesson about tobacco smoking. There was no significant difference between male and female students. Students aged $12-15$ years $(93.6 \%)$ were significantly more likely than students aged $16-17$ years $(89.1 \%)$ to have had a lesson or part of a lesson about tobacco smoking. There was no significant difference by socioeconomic level, or between urban areas or rural areas; however, students living in the North Coast Area Health Service (96.4\%) were significantly more likely to have had a lesson or part of a lesson about smoking, compared with the overall student population.

\section{Smoking behaviour}

In 2005, among students aged $12-17$ years, $10.3 \%$ were current tobacco smokers. There was no significant difference between male and female students. Students aged

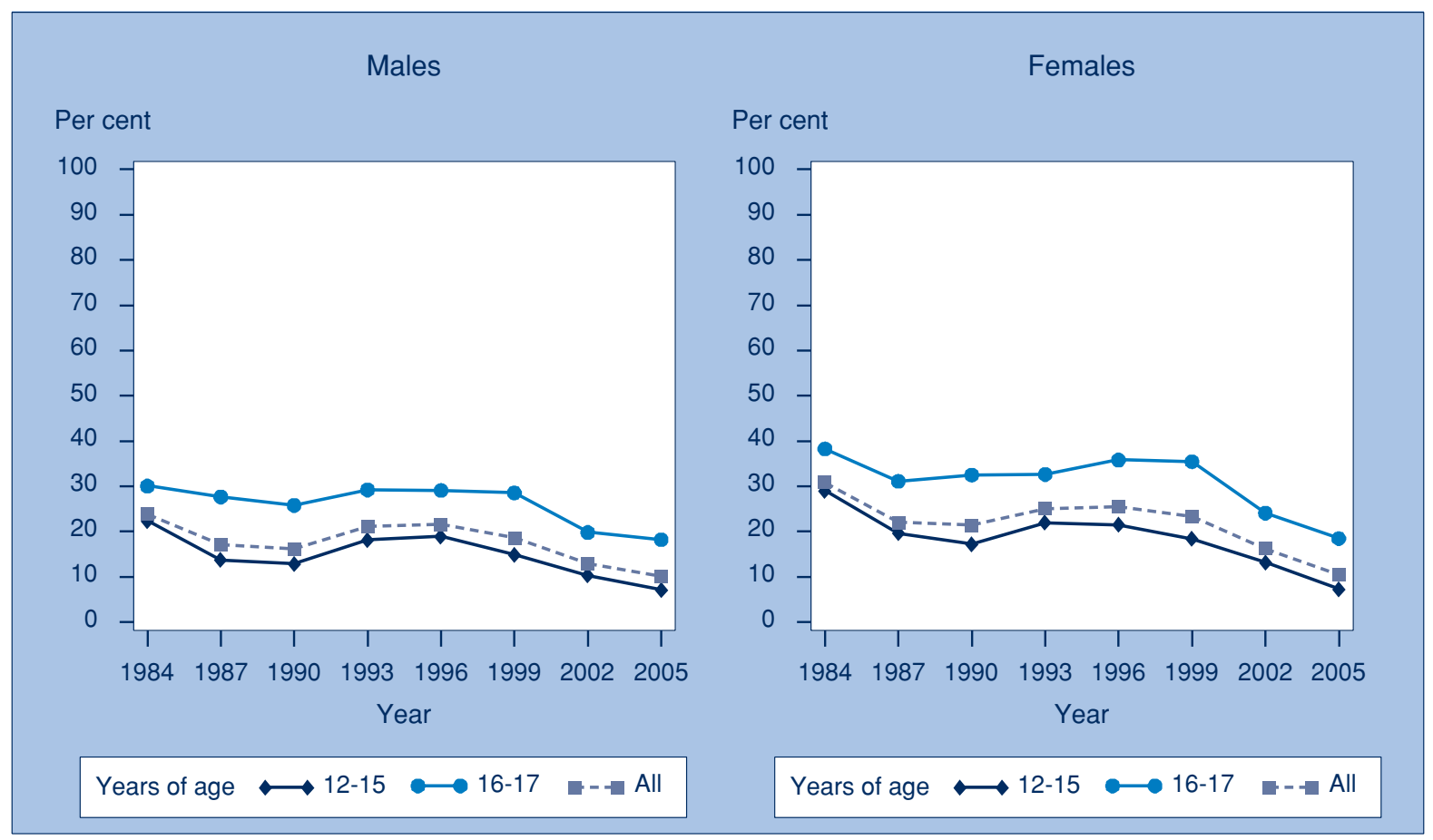

Fig. 1. Current tobacco smoker by year, students 12 to 17 years, NSW, 1984-2005

Source: New South Wales School Students Health Behaviours Survey: 2005 Report (HOIST). Sydney: Centre for Epidemiology and Research, NSW Department of Health. 
16-17 years (18.4\%) were significantly more likely than students aged $12-15$ years $(7.3 \%)$ to be current tobacco smokers. There was no significant difference by level of socio-economic disadvantage, or between rural areas and urban areas; however, students in the Greater Southern Area Health Service (14.1\%) were significantly more likely, and students in the Sydney South West Area Health Service $(6.9 \%)$ were significantly less likely, to be current tobacco smokers, compared with the overall student population. As shown in Figure 1, there has been a significant decrease in the proportion of students who are current tobacco smokers, between 1984 (27.3\%) and 2005 $(10.3 \%)$.

\section{Smoking addiction}

In 2005, among students aged 12-17 years who were current tobacco smokers, $21.3 \%$ thought they were addicted to tobacco. There was no significant difference between males and females, by level of socio-economic disadvantage, or between rural areas and urban areas; however, students in the Greater Western Area Health Service were significantly more likely to think they were addicted to tobacco $(58.6 \%)$, compared with the overall student population. There has been no significant change in the proportion of students who think they are addicted to tobacco between 2002 and 2005 .

\section{Smoking influences}

In 2005, among students aged $12-17$ years, $56.9 \%$ thought smoking by celebrities encouraged young people to take up smoking. There was no significant difference between males and females, between age groups, by level of socio- economic disadvantage, or between rural areas and urban areas; however, students in the Sydney South West Area Health Service $(63.7 \%)$ were significantly more likely, and students in the Northern Sydney and Central Coast Area Health Service (50.8\%) were significantly less likely, to think smoking by celebrities encourages young people to take up smoking.

The next New South Wales School Students Health Behaviours Survey is in 2008.

\section{References}

1. United States Department of Health and Human Services. The health consequences of smoking: a report of the SurgeonGeneral. Atlanta, GA, USA: United States Department of Health and Human Services, Centers for Disease Control and Prevention, Office on Smoking and Health, 2004. Available at http://www.cdc.gov/tobacco/sgr/sgr_2004/index.htm. Accessed 4 January 2008.

2. Drug Strategy Branch. Smoking behaviours of Australian secondary school students in 2002. Monograph Series No. 54. Canberra: Australian Government Department of Health and Ageing, 2004.

3. Centre for Behavioural Research in Cancer. Smoking behaviours of Australian secondary school students in 2005. Melbourne: The Cancer Council Victoria, 2006.

4. National Drug Strategy. Environmental tobacco smoke in Australia. Canberra: Commonwealth Department of Health and Ageing, 2002.

5. Centre for Epidemiology and Research. New South Wales School Students Health Behaviours Survey: 2005 Report. Sydney: NSW Department of Health, 2007. Available at http://www.health.nsw.gov.au/publichealth/surveys/index.asp. Accessed 4 January 2008.

\section{BUG BREAKFAST IN THE BULLETIN}

\section{Infectious diseases in homeless people}

\section{Sian Rudge ${ }^{\mathrm{A}}$, Ian Webster $^{\mathrm{B}}$ and Ingrid van Beek ${ }^{\mathrm{C}}$}

${ }^{\mathrm{A}}$ NSW Trainee Public Health Officer, NSW Department of Health ${ }^{\mathrm{B}}$ Emeritus Professor of Public Health and Community Medicine, University of New South Wales

${ }^{\mathrm{C}}$ Kirketon Road Centre, South Eastern Sydney Illawarra Area Health Service

On census night in 2001 there were close to 27000 homeless people in New South Wales (NSW). Almost $25 \%$ of these people were young people between 12 and 18 years old. The rate of homelessness was higher for Aboriginal people than non-Aboriginal people, and higher in coastal, and rural and remote areas of NSW than in Sydney. Within Sydney, the rate of inner-city homelessness was six times higher than in the outer suburbs. ${ }^{1}$

Many risk factors are associated with homelessness, including financial burdens and limited housing options. Mental health problems, often combined with drug or alcohol abuse, are common. For young people one of the main causes identified for being homeless is family breakdown. This may involve substance abuse by parents, or physical or sexual abuse of the young person. ${ }^{1,2}$

The multiple causes and complexities of homelessness mean that the provision of adequate housing alone is often not enough. A co-ordinated approach to the management 